\title{
Vulnerability of uneven-aged forests to storm damage
}

\author{
Marc Hanewinkel ${ }^{1 *}$, Thomas Kuhn ${ }^{1}$, Harald Bugmann², Adrian Lanz ${ }^{1}$ and Peter Brang ${ }^{1}$ \\ ${ }^{1}$ Swiss Federal Institute for Forest, Snow and Landscape Research (WSL), Research Unit Forest Resources and Management, \\ Zuercherstr. 111, Birmensdorf CH-8903, Switzerland \\ ${ }^{2}$ Chair of Forest Ecology, Swiss Federal Institute of Technology (ETH), Universitätstrasse 16, Zürich CH-8092, Switzerland \\ *Corresponding author: Tel.: +41 447392238; E-mail: marc.hanewinkel@wsl.ch
}

Received 24 April 2013

\begin{abstract}
Uneven-aged forests are assumed to have a high stability against storm damage but have rarely been analysed for vulnerability to storm damage due to a lack of a sufficient empirical database. Here we model storm damage in uneven-aged forest to analyse major factors that may determine the sensitivity of this type of forests to storms based on a broad database. Data are derived of public forests in the canton Neuchâtel in West Switzerland that are dominated by silver fir and Norway spruce and managed since the beginning of the 20th century following a single-tree selection system. A unique dataset of periodical (every $5-10$ years) full inventories measuring the diameter of every single tree including salvage cuttings was available for the investigation. The time series reached back until 1920 and covered an area of 16000 ha divided into 3000 divisions. The effect of a major winter storm ('Lothar') in December 1999 on these forests was investigated using a subset of 648 divisions. The influence of the vertical stand structure on the vulnerability of storm damage was studied using logistic regression models. To facilitate the analyses, an index of closeness to a J-shaped distribution (LikeJ) based on the number of trees in different diameter classes was developed. Besides structural indices, variables representing stand characteristics, soil-related and topography-related variables were included. The results of our study show that the overall damage level of the investigated forests was rather low. The variables that entered the model for the unevenaged stands were different to those that are normally significant for even-aged stands. While variables like stand structure, the timing of the harvesting and topographic variables entered a multivariate statistical model as significant predictors, standard predictors for storm damage in even-aged stands such as stand density, thinning intensity or species composition were not significant. We hypothesize that the uneven-aged structure of the investigated forests may be one reason for the low damage level we observed but emphasize the need for more detailed research to support this conclusion.
\end{abstract}

\section{Introduction}

Stand structure is assumed to have an influence on the vulnerability of forests to storm damage. Nolet et al. (2012) developed an approach in which information on stand structure in wind damaged sugar maple poles was used as bio-indicator for wind intensity. Bonnesoeur et al. (2013) investigated windfirmness of two different stand structures in beech forests and found that the increase of risk with the increase of the bending moment coefficient was higher for high forests compared with coppice with standards. Mason (2002) hypothesizes lower storm damage vulnerability in uneven-aged forests due to a potentially higher individual stability of the trees. This is supported by Kenk and Guehne (2001) who show that especially large trees in irregular forests have favourable relations between height and diameter $(<80)$ indicating high individual stability. In a study on the economic performance of uneven-aged forests in the Black Forest area of Southwest Germany (Hanewinkel, 2001), uneven-aged forests showed a lower percentage of salvage cuttings than adjacent even-aged forests (Hanewinkel, 2002). While there is an extensive literature on storm damage vulnerability and storm damage modelling (recently reviewed in Hanewinkel et al. (2011)) that mainly deals with even-aged forests, empirical information on storm damage in uneven-aged forests is rare. Only few regional case studies with a limited database (Dvorak et al., 2001) specifically deal with the vulnerability of uneven-aged forests on the stand level to storm damage. This is a major research gap, as one of the main reasons for the conversion of even-aged to uneven-aged forest within 'close-to-nature' silvicultural programs that are currently ongoing in large forest areas in Central Europe (Spiecker et al., 2004) is an assumed lower vulnerability of the targeted highly structured forest stands to abiotic disturbances such as storms. Additional information on the stability of uneven-aged forests under the influence of storms - including events with high wind speeds - is therefore urgently needed.

\section{Goal of the study and research questions}

The goal of the study is to investigate how stable uneven-aged forests that are characterized by trees of different sizes (diameter 
and height) on a limited area (so-called typical 'Plenter' - forests after Schütz (2006) dominated by conifers) against storm damage. Specifically, we investigate the following research questions:

(1) What is the influence of the vertical stand structure on storm damage in uneven-aged stands?

(2) What is the influence of other stand characteristics (tree species, stand density...) on storm damage in uneven-aged stands?

(3) What is the influence of harvesting (intensity and timing) activities?

(4) What is the influence of soil characteristics (moisture and acidity) and of the topographic situation (exposure, shape of terrain, slope and elevation)?

Thus, the study focuses on the analysis of uneven-aged forests and does not provide for a comparison between even-aged and uneven-aged stands in terms of windthrow probability.

\section{Material and methods}

\section{Database}

The study is based on repeated inventories in public forests in the canton Neuchâtel in the Jura region of West Switzerland that are dominated by silver fir (Abies alba Mill.), Norway spruce (Picea abies Karst) and European beech (Fagus sylvatica L.). Since the beginning of the 20th century, these forests have been managed following a single-tree selection system ('Plenterwald'). Since 1920, the diameter at breast height (dbh) of all trees with $\mathrm{dbh} \geq 17.5 \mathrm{~cm}$ has periodically (every $5-10$ years) been measured, and salvage cuttings separately recorded, for 3000 divisions of $0.3-20$ ha (mean 6 ha) in an area of 16000 ha. A division is an inventory unit that may encompass several stands that can be separately described in a qualitative way (i.e. by a verbal stand description). However, the quantitative description (i.e. the inventory) and the management planning both take place on a division level. Thus, the divisions in our case are comparable to forest stands and are treated as such in our investigation. Callipering was done in $5-\mathrm{cm}$-dbh classes, e.g. the $25-\mathrm{cm}$ class includes all trees with dbh of $\geq 22.5 \mathrm{~cm}$ and $<27.5 \mathrm{~cm}$. For this study, we analysed the effect of a major winter storm ('Lothar') in December 1999 that caused $>200$ million $\mathrm{m}^{3}$ of damage in Europe. We selected 648 divisions based on the criteria: constant area, data consistency and inventory immediately before the storm. Divisions that had significantly changed their area, those with missing data or were the last inventory was $>10$ years before the storm were thus excluded from the dataset.

In addition to the information from the forest inventories, we used information on soils issued from site mapping in the region (Richard, 1965) and a digital elevation model with 25-m grid (DHM25) to analyse the topography of the study area in terms of exposure, slope, curvature and elevation.

Figure 1 shows a map of the study area (canton Neuchâtel) with the different forest areas.

The forests are mostly concentrated on the slopes and ridges of the Jura mountain ranges between 700 and 1300 m a.s.l.

\section{Statistical modelling approach}

\section{Target variable}

As the target variable (dependent variable), we selected the damage severity $S$ at the division level. The damage severity was defined as the sum of the basal area of all damaged trees divided by the total basal area of the division according to the most recent inventory before the storm 'Lothar', i.e. in the years from 1990 to 1999. In our analysis, we use a logistic regression technique with a binomial response, in which stands with a damage severity $S$ of $<5$ per cent are classified as not damaged $(n=$

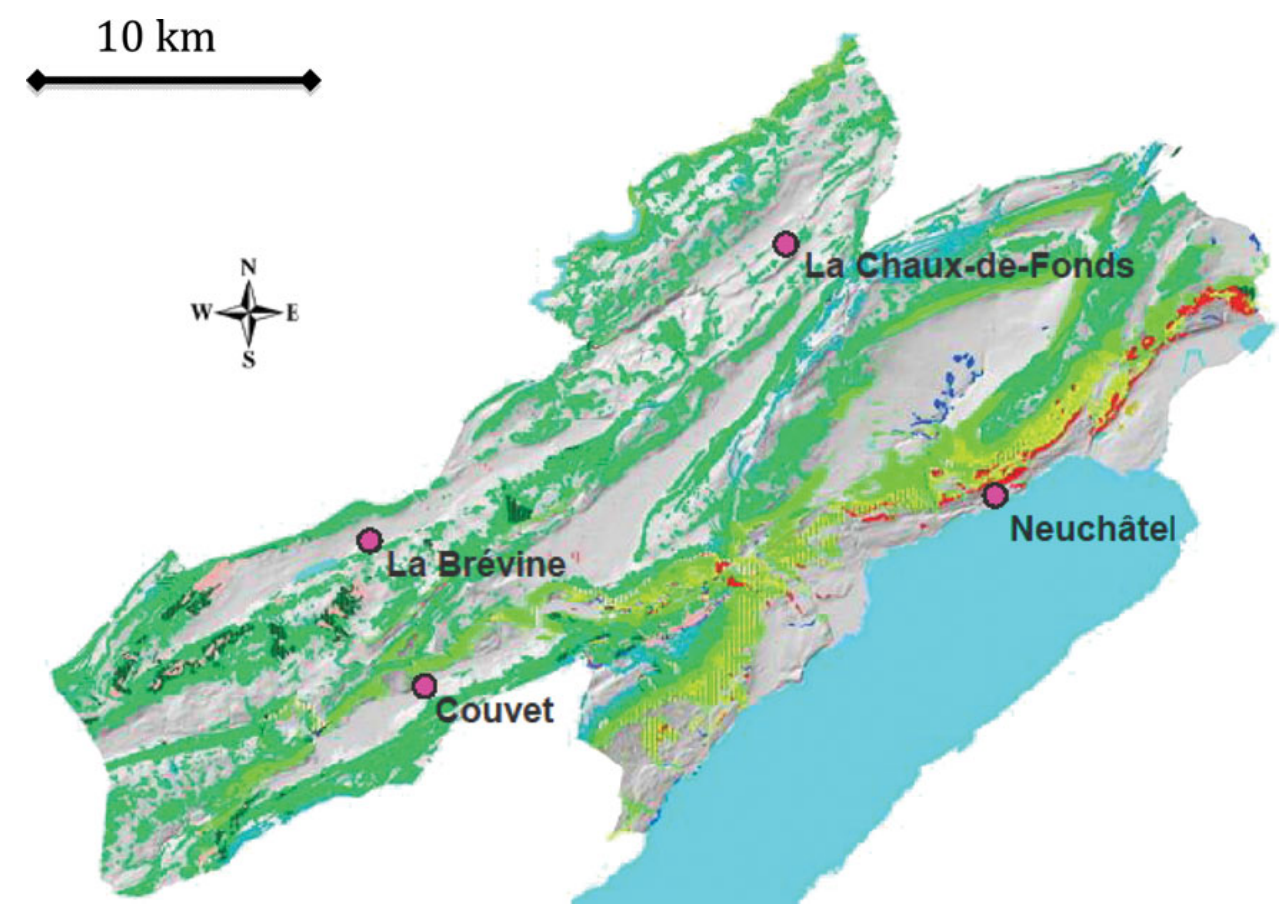

Figure 1 Study area in the canton Neuchâtel. Different colours show the forested areas with the forest associations according to the regional site map (Richard, 1965). 
509), and stands with a damage severity $S$ of $>5$ per cent are considered damaged $(n=139)$.

\section{Predictors (independent variables)}

We started with an initial set of 15 different predictors (independent or explaining variables) to analyse the vulnerability of the forests to storm damage in the study area. The initial selection was based on previous investigations of storm damage to forests that showed that, besides stand characteristics, terrain- and site-related parameters may affect damage (König, 1995; Fridman and Valinger, 1998; Jalkanen and Mattila, 2000; Mitchell et al., 2001; Dobbertin, 2002; Mason, 2002; Hanewinkel, 2005; Mayer et al., 2005; Schütz et al., 2006; Schmidt et al., 2010; Klaus et al., 2011; Valinger and Fridman, 2011; Albrecht et al., 2012; Albrecht et al., 2013). As reliable meteorological data such as high-resolution wind- or gust-speeds were not available for the study area, we did not include these parameters in our model. However, we checked whether there was a correlation between elevation and damage intensity, which was not the case.

The 15 initial predictors consisted of 9 variables describing stand characteristics, 4 variables concerning the topographic situation, 1 referring to soil conditions and 1 to the spatial distribution of the damage. We put special emphasis on describing the stand structure and investigated several indices on structural diversity of forest stands.

\section{Soil and terrain characteristics}

The variables describing soil characteristics were derived from the site map of the canton Neuchâtel. Using ArcGIS, the forest maps were intersected with the site maps, and each division was assigned to the site unit with the largest area in the division. Based on a regional description of the site units (Richard, 1965), the forest sites in the study area were grouped into four categories according to their position within the ecogram (Ellenberg and Klötzli, 1972): 1 - acid, 2 - central, 3 - moist and 4 - dry. These categories are standard categories that are used to classify soils and related plant associations in Europe. Forest sites of Category 2 (central) are thus in the centre of the ecogram, i.e. they occur on soils that are neither very moist nor dry and are in a pH range between slightly acid and neutral.

In order to describe the topographic situation of the study area, the variables exposure, slope, elevation (height above sea level) and curvature were calculated for each division, using ArcGIS and a digital elevation model with 25-m resolution (DGM25). Exposure was defined as a categorical variable with two categories: 1 - NE-E-SE-S and 2 - SW-W-NW-N, according to the major wind direction ( $\mathrm{SW}-\mathrm{W}-\mathrm{NW}$ ) in the study area. The curvature of the divisions describes forest areas with a positive curvature as convex (i.e. ridges) and those with a negative curvature as concave (i.e. hollows). The curvature was calculated as the (horizontal) curvature at the right angle in the direction of the maximum slope (for details of the calculation see ESRI (2012)).

We made no effort to include wind-related parameters like wind speed or gustiness in our model. We know from a reanalysis of the wind speeds on 26th of December 1999 (Meteoswiss, 2009) that the wind speeds in the study area were particularly high and that they did not much differ between lower and higher elevations. The cold front of the winter storm hit Switzerland at 09.00 UTC in the area of the Neuchâtel Jura and crossed the mountain range within half an hour. In La Brévine (1043 m a.s.l.), maximum wind speeds of $157 \mathrm{~km} \mathrm{~h}^{-1}$ were measured, in Delémont (413 m) even $170 \mathrm{~km} \mathrm{~h}^{-1}$ and on the Chasseral at $1600 \mathrm{~m}$ a.s.l. only marginally higher $177 \mathrm{~km} \mathrm{~h}^{-1}$. The rather high spatial resolution of our data (the average size of a division is $\sim 5 \mathrm{ha}$ ) would have required a grid of $200 \times 200$ to $300 \times 300 \mathrm{~m}$ for wind data of the storm Lothar, a resolution that is at the moment impossible to reach, even with very advanced meso-scaled models (see e.g. Schmoeckel and Kottmeier (2008)).

\section{Stand characteristics}

Besides basal area $\left(\mathrm{m}^{2} \mathrm{ha}^{-1}\right)$, standing volume $\left(\mathrm{m}^{3} \mathrm{ha}^{-1}\right)$, tree species composition (per cent of basal area of Norway spruce, silver fir and European beech), the intensity of harvesting (per cent of basal area removed in the 8 years before the storm) and time (years) without harvesting (calculated as the mean of the time difference between the year(s) of the intervention(s) and the year 2000, weighted with the intensity of the intervention when more than one intervention had taken place) were used as predictors. A co-linearity between the three predictors describing the tree species is likely (because they sum up to 100 per cent in most stands); therefore, we tested also two orthogonal contrast, i.e. indictor variables for stands with a percentage of broadleaves (beech) of $>25$ per cent vs. stands with a percentage of broadleaves of $<25$ per cent, and a second variable indicating stands with a proportion of spruce that is higher than the proportion of fir vs. stand with a proportion of fir being lower than the proportion of spruce. The proportions are defined on the amount of basal area in both variables.

\section{Stand structure}

We tested several indices to describe the stand structure of uneven-aged stands. In a first approach, we tried the coefficient of variation of the diameter distribution $\left(C_{\mathrm{DBH}}\right)$ according to Sterba and Zingg (2006), a distance-independent indicator for the vertical structure of a forest stand that is calculated as follows:

$$
C_{\mathrm{DBH}}=100 \times \mathrm{S}_{\mathrm{DBH}} / \bar{X}_{\mathrm{DBH}},
$$

with $s_{\mathrm{DBH}}=$ standard deviation of the DBH classes and $\bar{X}_{\mathrm{DBH}}=$ mean $\mathrm{DBH}$. However, we found that this coefficient, as many other indices that we initially analysed, does not really characterize the diameter distribution that is used as a guideline for forest management in the study area that is strictly based on an inverse J-shaped distribution of the diameter classes. For an analysis testing structural diversity in a very broad sense, a simple, modelfree index would have been better. However, our aim was to investigate how the management leading to a very specific type of structural diversity (i.e. the typical inverse J-shaped diameter distribution) that guarantees the necessary equilibrium to keep the steady state of the uneven-aged stand would influence storm damage vulnerability. We therefore developed a simple index describing the vertical structure of an uneven-aged stand based on the number of stems per hectare in different diameter classes that we called index of closeness to J shape (LikeJ).

This index is based on the diameter distribution (number of stems displayed as a function of diameter classes) of the stands, which describes the vertical stand structure of uneven-aged forests. LikeJ includes three different criteria that are combined using a scoring system:

(i) the number of small trees, i.e. in the diameter classes 20,25 and $30 \mathrm{~cm}$ (ii) the number of large trees, i.e. trees in the diameter classes $\geq 55 \mathrm{~cm}$

(iii) the diameter class with the maximum number of trees

For each of these criteria, a scoring system was developed based on reference values for uneven-aged forests in a 'Plenter'-equilibrium according to the model by Schütz (1975) from the municipal forests of Couvet (Favre and Oberson, 2002). The forests of Couvet grow in the centre of the study area and have been managed as model 'Plenter'-forests over the last century. The reference number of stems for criterion (i) (small trees diameter classes 20, 25 and $30 \mathrm{~cm}$ ) is between 150 and 170, and for criterion (ii) (large trees $\geq 55 \mathrm{~cm}$ ) is between 25 and 45 per hectare (Favre and Oberson, 2002), which resulted in a maximum score of 4 for both criteria (Table 1).

Table 1 gives a detailed overview of the scoring system. The highest index of LikeJ is reached at a score of 10 in divisions with a structure resembling a model Plenter-forest structure, while divisions that deviate from 
Table 1 Scoring system for the index of closeness to J shape (LikeJ)

\begin{tabular}{|c|c|c|c|c|c|}
\hline \multicolumn{2}{|c|}{$\begin{array}{l}\text { Number of small } \\
\text { trees }(20-30 \mathrm{~cm})\end{array}$} & \multicolumn{2}{|c|}{$\begin{array}{l}\text { Number of large } \\
\text { trees }(>55 \mathrm{~cm})\end{array}$} & \multicolumn{2}{|c|}{ Dbh class with max. $N$} \\
\hline$\left(\mathrm{Nha}^{-1}\right)$ & Score & $\left(\mathrm{Nha}^{-1}\right)$ & Score & Dbh class (cm) & Score \\
\hline$\geq 170$ & 4 & $\geq 65$ & 0 & $\geq 30$ & 0 \\
\hline $160-170$ & 4 & $60-65$ & 0.8 & 25 & 1 \\
\hline $150-160$ & 4 & $55-60$ & 1.6 & 20 & 2 \\
\hline $140-150$ & 3.6 & $50-55$ & 2.4 & & \\
\hline $130-140$ & 3.2 & $45-50$ & 3.2 & & \\
\hline $120-130$ & 2.8 & $40-45$ & 4 & & \\
\hline $110-120$ & 2.4 & $35-40$ & 4 & & \\
\hline $100-110$ & 2 & $30-35$ & 4 & & \\
\hline $90-100$ & 1.6 & $25-30$ & 4 & & \\
\hline $80-90$ & 1.2 & $20-25$ & 3.2 & & \\
\hline $70-80$ & 0.8 & $15-20$ & 2.4 & & \\
\hline $60-70$ & 0.4 & $10-15$ & 1.6 & & \\
\hline \multirow[t]{2}{*}{$<60$} & 0 & $5-10$ & 0.8 & & \\
\hline & & $<5$ & 0 & & \\
\hline
\end{tabular}

The overall score is calculated by summing up the sub-scores for the three different columns (number of small trees, number of large trees and diameter (dbh) class with the maximum number of trees (max. N)). Maximum score (max. closeness) is 10. References numbers for the number of trees in the sub-scores are based on Favre and Oberson (2002).

such model structures, e.g. by fewer or more large trees, have lower scores. Table 1 shows that criteria (i) and (ii) are weighted twice compared with criterion (iii). For criterion (iii), only divisions with the maximum number of trees in the smallest diameter classes ( 20 or $25 \mathrm{~cm}$ ) scored to guarantee the typical inverse $\mathrm{j}$-shaped diameter-distribution curve. Divisions with $>170$ small trees per hectare also achieved the maximum score for criterion (i). The index - including the scoring and weighting system - was developed in an iterative process such that stands with a reverse J-diameter distribution according to the model by Schütz (1975) should get the maximum scores whereas uniform forests should achieve the minimum scores.

\section{Spatial distribution of the damage}

As storm damage cannot be expected to be evenly distributed over the whole study area, we tested the spatial autocorrelation of the damage severity $S$ (see the target variable section) with two different definitions of neighbour divisions and two test statistics. Both neighbour definitions were based on distances between division centroids, once including the next (closest) $k=3$ divisions and on the other hand including divisions within a distance between 100 and $2100 \mathrm{~m}$, the latter resulting in an average number of 33 neighbours per division (4 divisions with only 1 neighbour, 1 division with 99 neighbours). The two test statistics were Moran's I and Geary's C. The statistics standard deviates are between 8.2 (Geary's C, $k=3$ ) to 20.1 (Moran's I, 100-2100 m) and indicate a highly significant spatial autocorrelation between the division's damage severities $S$.

Therefore, we introduced an auto-covariate (Dormann et al., 2007) in the logistic regression, which is, for each division, the mean damage severity $S$ over the $k=3$ neighbouring divisions.

Table 2 gives an overview of all variables that were initially included in the statistical analysis.
Table 2 Overview on the explaining variables (predictors) initially tested within the statistical modelling

\begin{tabular}{|c|c|c|}
\hline Name & Acronym & Type - unit (Range) \\
\hline \multicolumn{3}{|l|}{ Soil and terrain characteristics } \\
\hline Soil type & St & Category $(1-4)$ \\
\hline Exposure & $\exp$ & Category (1-2) \\
\hline Curvature & cur & Continuous $^{1}(-4$ to +4$)$ \\
\hline Elevation & hasl & Continuous (m) \\
\hline Slope & slo & Continuous (\%) \\
\hline \multicolumn{3}{|l|}{ Stand characteristics } \\
\hline Standing volume & vol & Continuous $\left(\mathrm{m}^{3} \mathrm{ha}^{-1}\right)$ \\
\hline Basal area & $\mathrm{ba}$ & Continuous $\left(\mathrm{m}^{2} \mathrm{ha}^{-1}\right)$ \\
\hline$\%$ basal area beech & \%be & Continuous (\%) \\
\hline$\%$ basal area spruce & $\%$ sp & Continuous (\%) \\
\hline$\%$ basal area fir & $\%$ fi & Continuous (\%) \\
\hline Intensity of harvesting & ina & Continuous (\%) \\
\hline Time without harvesting & tli & Continuous (y) \\
\hline \multicolumn{3}{|l|}{ Stand structure } \\
\hline $\begin{array}{l}\text { Coefficient of variation of the } \\
d b h\end{array}$ & $C_{d b h}$ & Continuous (\%) \\
\hline Index of closeness to J shape & LikeJ & Continuous $^{1}(1-10)$ \\
\hline \multicolumn{3}{|l|}{ Spatial distribution of damage } \\
\hline $\begin{array}{l}\text { Mean damage intensity of } \\
\text { geographical neighbours }\end{array}$ & $\mathrm{h}$ & Continuous (\%) \\
\hline
\end{tabular}

Detailed descriptions see text.

${ }^{1}$ dimensionless.

\section{Choice of the model}

In order to investigate the influence of the predictors on the observed stand damages, we fitted a generalized linear regression model of the form

$$
\operatorname{logit}(y)=\boldsymbol{X} \boldsymbol{\beta}+\boldsymbol{\rho} \boldsymbol{A}+\boldsymbol{\varepsilon}
$$

where $\boldsymbol{\beta}$ is the vector of coefficients for an intercept term and the explanatory variable $\boldsymbol{X}$, and $\boldsymbol{\rho}$ is the coefficient of the auto-covariate $\boldsymbol{A}$ addressing the spatial-autocorrelation of damage severities in the study area. $\boldsymbol{y}$ is the binary response, i.e. the likelihood that a storm damage of $>5$ per cent will occur and an error term $\boldsymbol{\epsilon}$.

All calculations have been done with the procedure GLM of the R statistical package R (Bivand, 2013;R_development_core_team, 2013)

To develop the final model, we started with a first model that included all predictors except for standing volume as it is strongly correlated with basal area. Checking for multiple interactions between predictors, we developed an initial set of 21 candidate models. We used Akaike's Information Criterion (AIC) (Akaike, 1974) to compare the performance of the models for best data fit (Anderson et al., 2000). From the candidate models with the best AIC scores, we developed the final model by stepwise backward regression, consecutively excluding the predictors that did not improve the performance of the model.

Thus, the predictors: soil condition, coefficient of variation of the diameter distribution $\left(\mathrm{C}_{\mathrm{DBH}}\right)$, basal area and standing volume, height above sea level and harvesting intensity were removed from the model. From the variables describing the tree species mixture, the percentage of beech (basal area) remained as a significant predictor for storm damage severity. We checked the residuals of the models to analyse further needs for transforming input variables, which proved to be unnecessary, and we also found that 


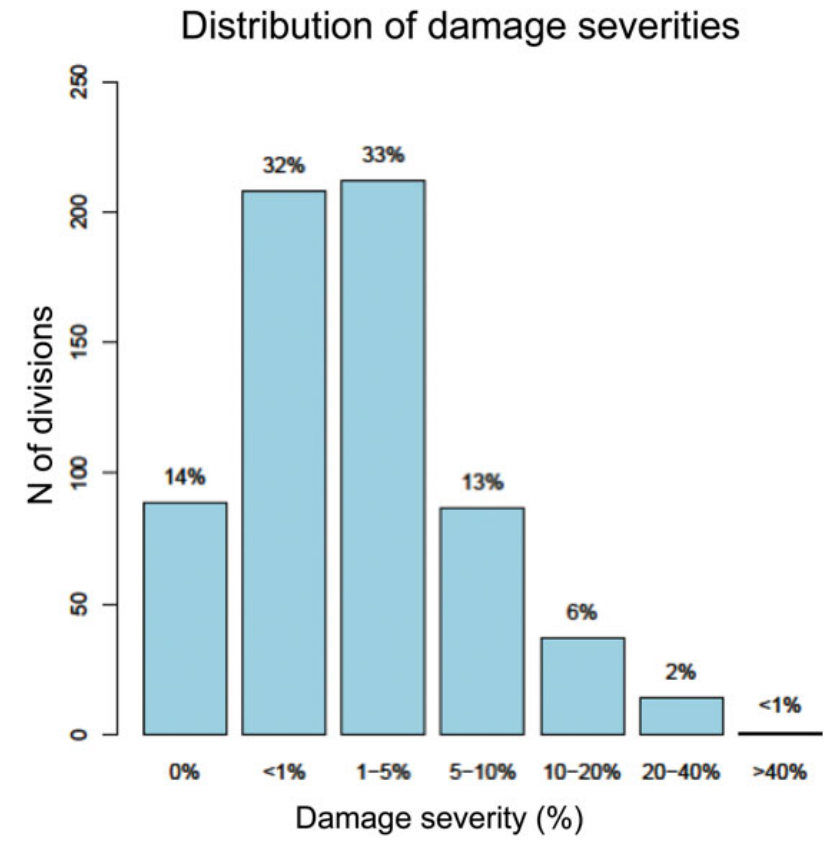

Figure 2 Damage severities in the forest divisions ( $n=648$ ) of the study area.

the auto-covariate completely removed the spatial autocorrelation from the residuals.

\section{Results}

\section{Distribution of the target variable}

The overall level of damage is rather low (Figure 2). In almost 80 per cent of the divisions, the damage severity is $<5$ per cent. Fourteen per cent of the divisions have not been damaged at all by the storm 'Lothar'. The highest damage severity is 42 per cent and occurred in only 1 division.

\section{Statistical model}

The statistical parameters (coefficients, P-values, level of significance) for the final selected model with the lowest AIC score are given in Table 3.

The final model with significant predictors for storm damage includes the following:

- the severity of storm damage in neighbouring stands ( $f$ ): the occurrence of storm damage in neighbouring stands increases the probability for storm damage in a given stand;

- the exposure of the stand (asp): (North) West exposition (asp1) in contrast to (South) East exposition slightly increases the likelihood of storm damage;

- the slope of the terrain (slo): the likelihood for storm damages decreases with the slope of the terrain for eastern exposed stands (less storm damage on steep slopes) and increases with the slope for western exposed stands (higher storm damage on steep slopes);
- the curvature of the terrain (cur): the likelihood for storm damage increases with a curvature of the ground surface changing from an extremely concave (ground depression) to an extremely convex surface (hill);

- the percentage of beech (ghe): storm damage likelihood decreases with a higher percentage of beech (basal area).

- number of years since the last intervention (lot): storm damage likelihood decreases with the number of years passed since the last sivicultural intervention;

- Index of closeness to J shape (LikeJ): the likelihood for storm damage decreases with increasing index of LikeJ, i.e. the stand's DBH distribution approaching the optimal DBH distribution (according to a model for uneven-aged stands developed based on long-term observations in the region).

\section{Overall evaluation of the model}

Under logistic regression, the residual deviance under the model compared with the null deviance (intercept term only) can be used as a measure for the strength of the model (pseudocoefficient of determination 1 - (residual deviance/null deviance)). We get a pseudo-coefficient of determination of 0.38 , which indicates a reasonable fit, but also means that some important factors may not have been available in this study.

\section{Effect of closeness to J shape and years without harvest - descriptive statistics}

In order to get a more detailed impression of the strength of the effect of some of the significant parameters, we looked into the boxplots of the predictors 'index of closeness to J shape - LikeJ' and time without harvest.

The damage severity decreases by $>50$ per cent from 0.2 (Index of LikeJ $=0-1$ ) to $<0.1$ (LikeJ $=7-8$ ) (Figure $3 a-$ left). For LikeJ values of $>8$, no further decrease of the damage severity can be observed. Interestingly, the damage severity already decreases to a level of $<0.1$ from LikeJ-class $(0-1)$ to class ( $1-2)$. However, looking at the frequency distribution of the LikeJ-values (Figure. $3 b$ - right), we can detect that the first two classes each makes up for $<1$ per cent of the divisions, which makes interpretation difficult. Looking at Figure. 3b, we concede that the distribution of the divisions is skewed towards highly uneven-aged stands and that the number of divisions with a distinct even-aged structure is low. A further analysis of the strength of the effect of the parameter unevenness using the response function of the regression coefficient showed that the effect of LikeJ is limited to a maximum of 1 per cent change of damage severity per LikeJ class, i.e. an overall maximum impact of 10 per cent of the parameter unevenness between the lowest class (LikeJ =0) and the highest class (LikeJ $=10$ ).

Furthermore, damage severity decreases with increasing time elapsed since the last harvest intervention (Figure. 4).

The severity constantly decreases from 1 to 8 years without harvest before the storm event (Figure 4) showing a clear, though not strong effect of the timing of the harvest. On average, 1 year more time decreases the damage severity by $\sim 1$ per cent (s. Table 2). 
Table 3 Statistical parameters of the predictors of the final selected model, including interactive effects

\begin{tabular}{|c|c|c|c|c|c|c|}
\hline Coefficients & & Estimate & Standard error & Z-value & $\operatorname{Pr}(>|z|)$ & Level of significance \\
\hline Intercept & & 1.35290 & 0.71619 & 1.889 & 0.058890 & $* \star \star \star$ \\
\hline Auto-covariate & $f$ & 0.25670 & 0.03111 & 8.250 & $<2 \mathrm{e}-16$ & $* \star *$ \\
\hline Curvature & cur & 1.95866 & 0.59838 & 3.273 & 0.001063 & $* *$ \\
\hline Closeness to J shape & LikeJ & -0.15997 & 0.05958 & -2.685 & 0.007259 & $* \star$ \\
\hline Time without harvest & lot & -0.16152 & 0.05813 & -2.779 & 0.005461 & $* *$ \\
\hline Share of beech & ghe & -0.03563 & 0.01223 & -2.913 & 0.003580 & $* *$ \\
\hline Exposition & asp1 & -1.31395 & 0.65628 & -2.002 & 0.045273 & * \\
\hline Slope & slo & -0.13707 & 0.04128 & -3.320 & 0.000899 & $* * *$ \\
\hline Exposition: slope & asp1:slo & 0.15656 & 0.04502 & 3.477 & 0.000506 & $* * *$ \\
\hline
\end{tabular}

Exposure $1=$ easterly exposed sites. Estimated coefficients, including standard error and $P$-values, $n=648$. Significance levels: ${ }^{* * *}=0.001,{ }^{* *}=0.01$, ${ }^{*}=0.05,{ }^{* * *}=0.1$

A

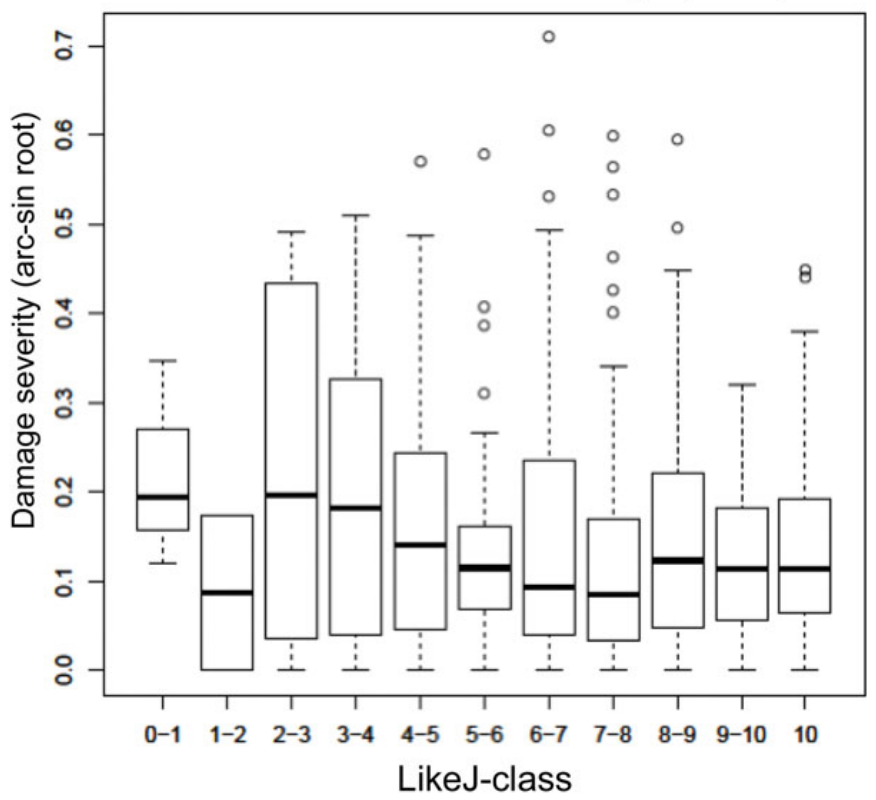

B

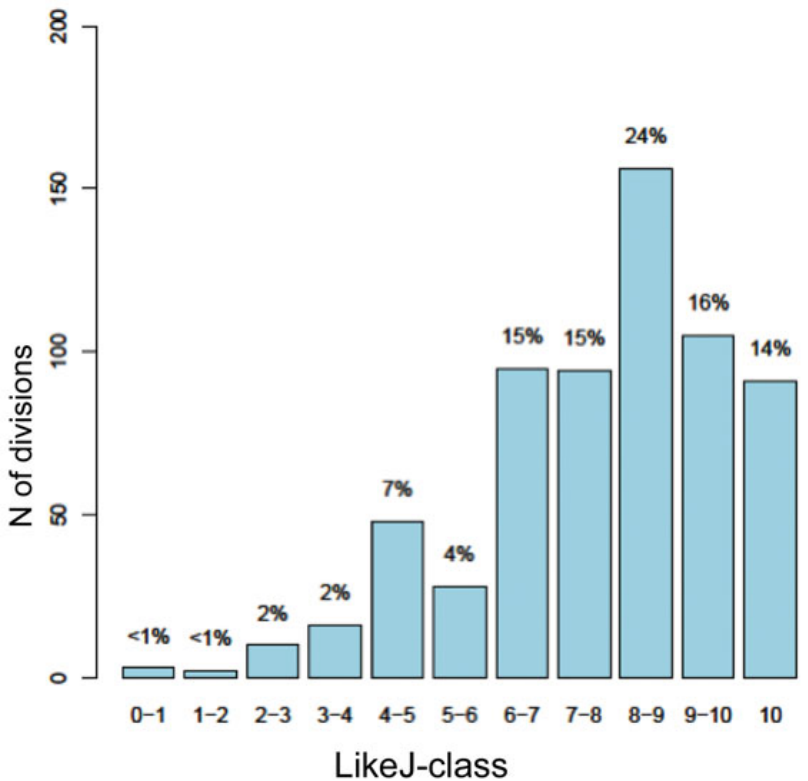

Figure 3 (a)(left): Effect of the closeness to J shape (LikeJ - see text) on the damage severity ( $n=648$ ). For reasons of clarity, damage severity ( $y$-axis) is depicted using the arc-sine-root transformation (Mosteller and Tukey, 1977). Note: The classes for damage severities are different to those in Figure. 2. (b) (right): Number of divisions ( $n=648$ ) according to classes of closeness to J shape (LikeJ - see text).

\section{Discussion}

\section{Database of the investigation}

The dataset that was available for the present investigation covering 3000 forest divisions on $>16000$ ha, and several decades is certainly unique. Even the reduction to 648 divisions by concentrating on one major storm event and the years 1990-1999 makes for a substantial database for the analysis of uneven-aged stands. However, because the dataset mainly originates from inventory and booking data, it has some limitations that influence the results: the inventory threshold of $\mathrm{dbh}=17.5 \mathrm{~cm}$ is particularly high compared with other investigations (Fridman and Valinger, 1998; Jalkanen and Mattila, 2000; Dvorak et al., 2001; Dobbertin, 2002; Valinger and Fridman, 2011). This affects structural indices like $C_{\mathrm{DBH}}$ (Sterba and Zingg, 2006) as it influences the relation of mean and standard deviation. The overall damage level of the forests in this study was rather low for this storm event, which had an influence on the discriminatory power of the variables under investigation. The population of forests included in this study was biased towards uneven-aged stands. This again limits the efficiency of classical structural indices, as we were not able to cover the full range from highly structured stands - that were well represented in our dataset - to structurally more uniform even-aged stands that are underrepresented. Furthermore, the data did not contain information on tree height, a parameter that has proven to be significant in many studies (Jalkanen and Mattila, 2000; Mitchell et al., 2001; Dobbertin, 2002; Mayer et al., 2005; Schmidt et al., 2010; Valinger and Fridman, 2011; Albrecht 
Influence of the timing of harvesting

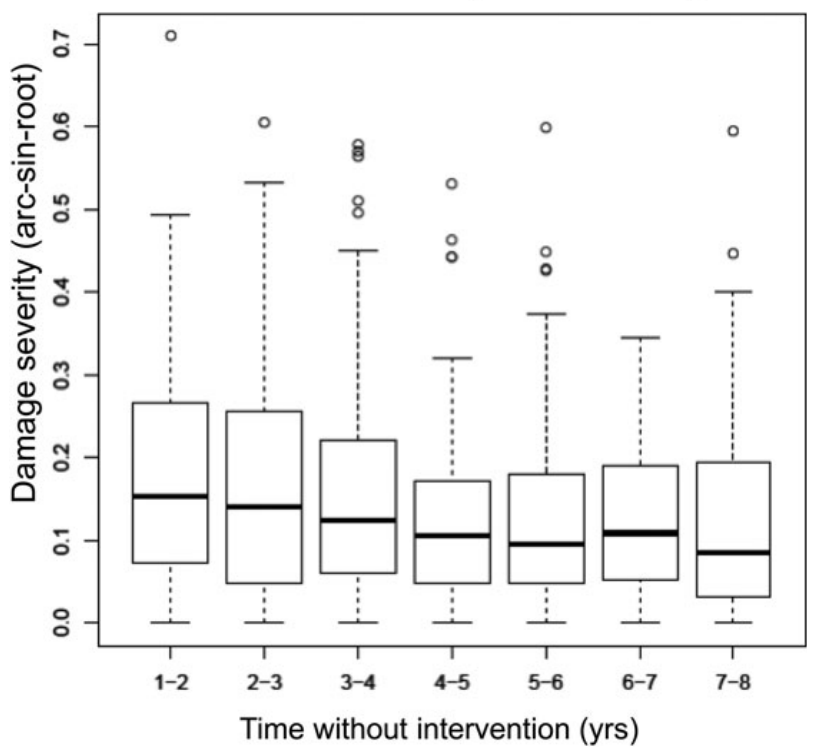

Figure 4 Influence of the timing of harvest (time elapsed since the last harvesting intervention) on the damage severity. For reasons of clarity, damage severity ( $y$-axis) is depicted using the arc-sine-root transformation (Mosteller and Tukey, 1977).

et al., 2012) nor on the spatial distribution of the trees. However, as we developed a stand-based model, the influence of individual tree positions as well as mean values for tree height (or for the highly correlated dbh) especially for these uneven-aged stands are very difficult to interpret. We would certainly have to expect differences in damage severities if our divisions had shown distinct differences in mean or absolute tree height.

\section{Modelling approach}

We used a Generalized Linear Model (GLM) with a logistic regression as a link function, a standard approach that has been applied in many studies on storm damage vulnerability of forests (König, 1995; Fridman and Valinger, 1998; Jalkanen and Mattila, 2000; Dvorak et al., 2001; Mitchell et al., 2001; Mayer et al., 2005; Schütz et al., 2006; Schmidt et al., 2010; Klaus et al., 2011; Valinger and Fridman, 2011;Albrecht et al., 2012). As an alternative to statistical models, 'artificial neural networks' have been used, specifically with incomplete and noisy datasets (Hanewinkel et al., 2004; Hanewinkel, 2005), which was not the case in this study. Other authors (Dobbertin, 2002;Albrecht et al., 2012) have studied storm damage in forests using 'classification and regression trees'. Besides the advantage of being easier to interpret, the great disadvantage of this approach is that you do not get any probabilities from these models. While only few studies exclusively rely on a literature analysis (Mason, 2002), mechanistic models (Peltola et al., 1999; Gardiner et al., 2008) are a common approach to investigate storm damage vulnerability of forests. However, so far these models are restricted to model storm damage vulnerability in rather uniform even-aged forests.

We used AIC as the criterion for model selection, a parameter that only delivers information on the relative strength of the winner model compared with other models but does not inform about the effective predictive power of the final model. However, the primary goal of this study was not to develop a model to predict storm damage in forest stands, but rather to analyse major influencing factors of the vulnerability of uneven-aged stands to storm damage.

\section{Influence of the predictors}

In the following sections, we discuss the influence of the different predictors on storm damage vulnerability along with the research questions that we have developed in the introduction.

\section{Vertical stand structure}

Looking at our research question 1 , we can conclude that the - vertical - stand structure has a significant influence on storm damage vulnerability of uneven-aged stands. Due to the high minimum size threshold during inventories in our study, the value range of existing structural indices like the $C_{\mathrm{DBH}}$ is distinctly lower than that in investigations with lower thresholds. Sterba and Zingg (2006) found mean values for $C_{\mathrm{DBH}}$ of 38.2 for even-aged and 72.9 for uneven-aged stand, whereas the divisions in our study showed values between 23.1 and 56.9. Unlike other authors (Dvorak et al., 2001; Dobbertin, 2002) who individually grouped the stand structure of the investigated forests based on field measurements, we developed a structural index using model-based reference numbers. Our index of closeness to J shape (LikeJ) entered our model as a statistically significant variable, indicating that stands with a structure closer to a J-shaped stem-distribution are less prone to storm damage than more uniform stands, which is in line with findings of other studies (Dvorak et al., 2001; Dobbertin, 2002). However, the influence of the stand structure is rather small. Under ceteris-paribus conditions (i.e. all other influencing variables are kept constant), the maximum influence of the stand structure on the vulnerability, i.e. the difference between a stand with the highest and lowest unevenness, is at $~ 10$ per cent of damage severity. This means that the damage level can be decreased from 20 per cent in LikeJ-class 2 to 10 per cent in LikeJ-class 10 (Figure. 3a). The potentially higher stability of uneven-aged forests is often assigned to a higher individual stability of the single trees (Mason, 2002), e.g. characterized by a lower h/ $\mathrm{d}$-value, a factor that we did not investigate in our study.

We did not include a comparison between even-aged and uneven-aged forests in our study, as this cannot be made at the stand level only. Even-aged management leads to the development of stands of various ages at the landscape level that will have very different susceptibilities to windthrow. A full comparison between even-aged and uneven-aged management should consider all states of development of even-aged stands.

\section{Other stand characteristics}

With respect to research question 2 of our study, the influence of other stand characteristics on storm damage vulnerability of uneven-aged stands was surprisingly low. We were not able to identify an effect of the stand density, a factor that appears to be significant in several studies (Dvorak et al., 2001; Mitchell et al., 2001; Mason, 2002; Valinger and Fridman, 2011). The overall influence of the predictor 'species' is rather low, except for a significant 
influence of the percentage of beech. No influence of the percentage of Norway spruce was detected, which is partly contradictory to many studies dealing with storm damage to forests (König, 1995; Jalkanen and Mattila, 2000; Dvorak et al., 2001; Dobbertin, 2002; Mayer et al., 2005; Schütz et al., 2006; Hanewinkel et al., 2008; Schmidt et al., 2010; Klaus et al., 2011). The reason therefore might be that the distribution of the tree species in our dataset with a large amount of mixed stands and a lack of pure stands is rather uniform across the divisions in our study compared with other investigations that were able to compare pure and mixed stands of different tree species.

\section{Harvesting}

Concerning research question 3 , only the timing of the harvesting, i.e. the number of years elapsed since the last harvesting, had a clear significant influence on the vulnerability. This effect can be found in many studies on storm damage (König, 1995; Dvorak et al., 2001; Mitchell et al., 2001; Valinger and Fridman, 2011; Albrecht et al., 2012). Our study shows a destabilizing effect for a time of up to 8 years, whereas Albrecht et al. (2012) found an influence of that factor of up to 10 years. Usually this is - at least for even-aged stands - assigned to the temporary interruption of the canopy. In contrast to the results of other studies (e.g. Albrecht et al. (2012)), we did not detect an influence of the harvesting intensity. Here we hypothesize that harvesting in developed uneven-aged stands is a rather uniform type of intervention that does not vary in the same way as in even-aged forests where thinning intensity strongly varies according to the type of the applied thinning (e.g. high thinning, thinning from below, target diameter harvesting...).

\section{Soil and topography}

Our research question 4 deals with the influence of soil and topography. Soil is a predictor that is included in many investigations on storm damage (Fridman and Valinger, 1998; Jalkanen and Mattila, 2000; Dvorak et al., 2001; Mitchell et al., 2001; Dobbertin, 2002; Hanewinkel, 2005; Mayer et al., 2005; Schütz et al., 2006; Schmidt et al., 2010; Klaus et al., 2011; Albrecht et al., 2012). Generally soil moisture is assumed to have a significant influence on storm damage probability, specifically when highly vulnerable species such as Norway spruce grow on waterlogged soils (Hanewinkel et al., 2008;Schmidt et al., 2010). Although wet soils showed a tendency towards higher damage severity than dry soils in our study, this effect was masked by other effects in the multivariate analysis and did not enter the final model. Soil acidity, a predictor that was significant in one investigation (Mayer et al., 2005), did not have any effect in our study that took place in a relatively uniform region, characterized by limestone with little variation in soil acidity.

Topography is a predictor that also entered many statistical storm damage models (König, 1995; Fridman and Valinger, 1998; Jalkanen and Mattila, 2000; Dvorak et al., 2001; Mitchell et al., 2001; Dobbertin, 2002; Hanewinkel, 2005; Mayer et al., 2005; Schütz et al., 2006; Schmidt et al., 2010; Klaus et al., 2011; Albrecht et al., 2012). As the storm 'Lothar' was a typical winter storm that reached the study area from West (Meteoswiss, 2009), it is not surprising that westerly exposed divisions displayed a higher damage severity than those exposed to the East. However, in the multivariate statistical model, the predictor exposure entered the model in combination with the share of silver fir and slope. In combination with slope, exposure reveals significantly lower damage intensities of steep slopes, an effect that has often been observed for storm damage (Dvorak et al., 2001; Dobbertin, 2002; Mayer et al., 2005; Schütz et al., 2006; Klaus et al., 2011). However, in our study, the predictor is only significant in interaction with exposure to the East, whereas westerly exposed slopes do not show any higher damage severity than areas with less steep sites. We also detected a significant influence of the curvature of the terrain, with higher damage intensities on convex than on concave slopes, a predictor that also entered the multivariate model and that was also significant in other studies (Dobbertin, 2002; Klaus et al., 2011). Although increasing elevation can be generally linked to higher wind speeds, the variable was not significant in our study. Elevation as a predictor shows both directions as a predictor. In one study (Klaus et al., 2011), it was linked to higher storm damage, whereas in another investigation (Mayer et al., 2005), it was associated with lower damage intensities. The latter may be a sign of an adaptation of the root system to constantly higher wind speeds in higher elevations or simply the result of a general difficulty to get reliable information of the parameter 'wind' that includes aspects like gustiness that are very difficult to assess (Schütz et al., 2006; Gardiner et al., 2008; Albrecht et al., 2012; Kamimura et al., 2013).

\section{Conclusions}

Our investigation contributes to the knowledge of the vulnerability of uneven-aged forests to storm damage, a field of research that is currently characterized by empirical investigations dealing with either small areas (Dvorak et al., 2001) or with datasets containing almost no or only very few really uneven-aged forests (Dobbertin, 2002).

The results of our study show that uneven-aged stands display a specific vulnerability towards storm damage that differs in some aspects from that of even-aged stands. Stand structure (the index of closeness to J shape - LikeJ - as developed for this study,) the timing of the harvesting and topographic variables entered a multivariate statistical model as significant predictors in our investigation. However, standard variables that occur in many statistical models for storm damage in even-aged stands such as stand density, thinning intensity or species composition were not significant at all or only in interaction with other parameters. Looking at the comparably low damage level of the forests that we investigated and taking into account the rather high wind speeds in the area on the day of the storm 'Lothar' (Meteoswiss, 2009), we might conclude that long-term single-tree selection forestry has led to stable stand structures that were able to cope with a major storm event in the study area. However, in order to allow for general conclusions on the vulnerability of uneven-aged compared with even-aged forests, we intend to enlarge our database with more uniform forests stands, to investigate additional storm events and to include stand height values as predictor. The latter should be feasible by taking advantage of LIDAR information.

\section{Acknowledgements}

We greatly acknowledge the support by data delivery and discussion of Pascal Junod, Service de la Faune, des Forêts et de la Nature of the Canton Neuchâtel. 


\section{Conflict of interest statement}

None declared.

\section{References}

Akaike, H. 1974 A new look at statistical model identification. IEEE transac. automat. control AC-19, 716-723.

Albrecht, A., Hanewinkel, M., Bauhus, J. and Kohnle, U. 2012 How does silviculture affect storm damage in forests of south-western Germany? Results from empirical modeling based on long-term observations. Eur. J. For. Res. 131, 229-247.

Albrecht, A., Kohnle, U., Hanewinkel, M. and Bauhus, J. 2013 Storm damage of Douglas fir unexpectedly high compared to Norway spruce. Ann. For. Sci. 70, 195-207.

Anderson, D.R., Burnham, K.P. and Thompson, W.L. 2000 Null hypothesis testing: problems, prevalence, and an alternative. J. Wildlife Manag. 64, 912-923.

Bivand, R. 2013 spdep: Spatial dependence: weighting schemes, statistics and models. R package version 0.5-65. http://CRAN.R-project.org/ package $=$ spdep .

Bonnesoeur, V., Fournier, M., Bock, J., Badeau, V., Fortin, M. and Colin, F. 2013 Improving statistical windthrow modeling of 2 Fagus sylvatica stand structures through mechanical analysis. For. Ecol. Manag. 289, 535-543.

Dobbertin, M. 2002 Influence of stand structure and site factors on wind damage comparing the storms Vivian and Lothar. For. Snow Landscape Res. 1/2, 187-205.

Dormann, C., McPherson, J., Araújo, M., Bivand, R., Bolliger, J. and Carl, G. et al. 2007 Methods to account for spatial autocorrelation in the analysis of species distributional data: a review. Ecography 30, 609-628.

Dvorak, L., Bachmann, P. and Mandallaz, D. 2001 Sturmschäden in ungleichförmigen Beständen. Schweiz Z Forstwes 152, 445 - 452.

Ellenberg, H. and Klötzli, F. 1972 Waldgesellschaften und Waldstandorte der Schweiz. Mitt. Schweiz. Anst. Forstl. Versuchsw 48, 587-930.

ESRI. 2012 ArcGIS Resource Center. Desktop 10. Curvature (Spatial Analyst). http://help.arcgis.com/de/arcgisdesktop/10.0/help/index.html-//009z0000 00tw000000. (accessed on October, 2013).

Favre, L.A. and Oberson, J.M. 2002 Die 111-jährige Anwendung der Kontrollmethode im Gemeindewald von Couvet. http://www.ne.ch/neat/ site/jsp/rubrique/rubrique.jsp?StyleType=bleu\&CatId=5749. (accessed on March, 2013).

Fridman, J. and Valinger, E. 1998 Modelling probability of snow and wind damage using tree, stand, and site characteristics from Pinus sylvestris sample plots. Scand. J. For. Res. 13, 348-356.

Gardiner, B., Byrne, K., Hale, S., Kamimura, K., Mitchell, S., Peltola, H. and Ruel, J.C. 2008 A review of mechanistic modelling of wind damage risk to forests. Forestry 81, 447-461.

Hanewinkel, M. 2001 Financial results of selection forest enterprises with high proportions of valuable timber - results of an empirical study and their application. Schweiz Z Forstwes 152, 343-349.

Hanewinkel, M. 2002 Comparative economic investigations of even-aged and uneven-aged silvicultural systems: a critical analysis of different methods. Forestry 75, 473-481.

Hanewinkel, M. 2005 Neural networks for assessing the risk of windthrow on the forest division level: a case study in southwest Germany. Eur. J. For. Res. 124, 243-249.

Hanewinkel, M., Zhou, W. and Schill, C. 2004 A neural network approach to identify forest stands susceptible to wind damage. For. Ecol. Manag. 196, $227-243$.
Hanewinkel, M., Breidenbach, J., Neeff, T. and Kublin, E. 200877 years of natural disturbances in a mountain forest area - the influence of storm, snow and insect damage analysed with a long-term time-series. Can. J. For. Res. 38, 2249-2261.

Hanewinkel, M., Hummel, S. and Albrecht, A. 2011 Assessing natural hazards in forestry for risk management: a review. Eur. J. For. Res. 130, 329-351.

Jalkanen, A. and Mattila, U. 2000 Logistic regression models for wind and snow damage in northern Finland based on the National Forest Inventory data. For. Ecol. Manag. 135, 315-330.

Kamimura, K., Saito, S., Kinoshita, H., Kitagawa, K., Uchida, T. and Mizunaga, H. 2013 Analysis of wind damage caused by multiple tropical storm events in Japanese Cryptomeria japonica forests. Forestry. doi:10.1093/forestry/ cpt1011

Kenk, G. and Guehne, S. 2001 Management of transformation in central Europe. For. Ecol. Manag. 151, 107-119.

Klaus, M., Holsten, A., Hostert, P. and Kropp, J.P. 2011 An integrated methodology to assess windthrow impacts on forest stands under climate change. For. Ecol. Manag. 261, 1799-1810.

König, A. 1995 Sturmgefährdung von Beständen im Altersklassenwald. J.D. Sauerländer's.

Mason, W.L. 2002 Are irregular stands more windfirm? Forestry 75, 347-355.

Mayer, P., Brang, P., Dobbertin, M., Hallenbarter, D., Renaud, J.-P. and Walthert, L. et al. 2005 Forest storm damage is more frequent on acidic soils. Ann. For. Sci. 62, 303-311.

Meteoswiss. 2009 Orkan Lothar - 10 Jahre danach. http://www. meteoschweiz.admin.ch/web/de/wetter/wetterereignisse/orkan_lothar_10.html. (accessed on October, 2013).

Mitchell, S., Hailemariam, T. and Kulis, Y. 2001 Empirical modeling of cutblock edge windthrow risk on Vancouver Island, Canada, using stand level information. For. Ecol. Manag. 154, 117-130.

Mosteller, F. and Tukey, J.W. 1977 Data Analysis and Regression: A Second Course in Statistics. Addison-Wesley.

Nolet, P., Doyon, F. and Bouffard, D. 2012 Predicting atem windthrow probability in a northern hardwood forest using a wind intensity bio-indicator approach. Open J. For. 2, 77-87.

Peltola, H., Kellomäki, S., Väisänen, H. and Ikonen, V.-P. 1999 A mechanistic model for assessing the risk of wind and snow damage to single trees and stands of Scots pine, Norway spruce, and birch. Can. J. For. Res. 29, 647-661. R_development_core_team. 2013 R: A Language and Environment for Statistical Computing. R Foundation for Statistical Computing.

Richard, J.L. 1965 Extrait des cartes phytosociologiques des forêts du canton. Neuchâtel. Beitr. geobat. Landesaufnahme d. Schweiz 47, 48.

Schmidt, M., Hanewinkel, M., Kändler, G., Kublin, E. and Kohnle, U. 2010 An inventory-based approach for modeling single tree storm damage experiences with the winter storm 1999 in southwestern Germany. Can. J. For. Res. 40, 1636-1652.

Schmoeckel, J. and Kottmeier, C. 2008 Storm damage in the black forest caused by the winter storm 'Lothar'. Part 1: airborne damage assessment. Nat. Hazards Earth Syst. Sci. 2, 1-9.

Schütz, J.P. 1975 Dynamique et conditions d'équilibre de peuplements jardinés sur les stations de la hêtraie à sapin. Schweiz Z Forstwes 126, 637-671.

Schütz, J.P. 2006 Demographic sustainability of beech plenter forests. Ann. For. Sci. 63, 93-100.

Schütz, J.P., Götz, M., Schmid, W. and Mandallaz, D. 2006 Vulnerability of spruce (Picea abies) and beech (Fagus sylvatica) forest stands to 
storms and consequences for silviculture. Eur. J. For. Res. 125, Sterba, H. and Zingg, A. 2006 Abstandsabhängige und abstands291-302.

Spiecker, H., Hansen, J., Klimo, E., Skovsgaard, J., Sterba, H. and von Teuffel, K. (eds). 2004 Norway spruce conversion: options and consequences. European Forest Institute, Research Report 18. Brill, S. Leiden, Boston, Köln. unabhängige Bestandesstrukturbeschreibung. Allgemeine Forst und Jagdzeitung 177, 169-176.

Valinger, E. and Fridman, J. 2011 Factors affecting the probability of windthrow at stand level as a result of Gudrun winter storm in southern Sweden. For. Ecol. Manag. 262, 398-403. 